\title{
Controlled Ageing of High Voltage Pylons
}

\author{
Peter Polák, Martin Kasenčák, Jakub Porubčan, Michal Novoveský, Vladimír Piussi \\ First Welding Company Inc. \\ Slovakia
}

\begin{abstract}
This contribution is dedicated to issues of long term safe service of high-voltage pylons, which are during service loaded by variable loading with simultaneous acting of external environment. There were proved the procedures ensuring that the limit state will not occur during the period of technical life and the service will be safe for a long time. A draft of diagnostic procedures was elaborated. The maintenance and repair procedures, assuring the safety of service until next inspection are planned on the basis of application of analytic methods of dynamic fracture mechanics. Controlled ageing allows to save high economic values at spending considerable lower costs for inspection and maintenance.
\end{abstract}

Keywords-pylons; controlled ageing; residual life; risk based inspection

\section{INTRODUCTION}

The construction of high-voltage lines transmitting $110 \mathrm{kV}$, $220 \mathrm{kV}$ and $400 \mathrm{kV}$ started in Europe in the 40-ties of the past century. Most of original pylons are in service till present days. Replacement is actually performed only for the reason of pylon breakdowns.

\section{LOADING OF PYLONS}

The construction of high-voltage lines transmitting $110 \mathrm{kV}$, $220 \mathrm{kV}$ and $400 \mathrm{kV}$ started in Europe in the 40-ties of the past century. Most of original pylons are in service till present days. Replacement is actually performed only for the reason of pylon breakdowns. Pylons are loaded by random loading processes. Breakdowns usually occur due to icing, strong side wind and/or by combination of both. Gusty wind causes the galloping of ropes. In general, four types of dynamic loading occur which are caused by unfavourable weather conditions. These are: aeolic oscillations of ropes, galloping oscillation of ropes, dynamic impact at shedding of ice from the rope and detachment of whirls on the pylons and insulators. Danger of sudden breakdown occurs at resonance, when the loading frequency is equal as the own frequency of pylons. Breakdown of one pylon used to be the initiator of the socalled domino effect - a progressive breakdown of greater number of pylons.

\section{A. Response to External Loading}

The rate and dynamics of external loading cause a response in the critical points of structure by damage cumulation. In the first phases this is an event without visible signs on material surface, when the incubation phase of fatigue failure on the level of structure and substructure (crystals) takes place, mainly by growth in density of dislocations. This stage of development of fatigue cracks is usually affected by the stress concentration from notches and also by residual stresses, mainly in the zone of welded joints. After incubation stage of fatigue process, the stage of fatigue crack growth follows. The damage process terminates by rupture of the remaining cross section. In case of existence of surface defects (crack, lack of fusion, cold lap, etc,) the incubation phase is abandoned and the entire process of fatigue consists only in the fatigue crack growth.

By the Griffith - Irwin (1957) theory, the main criterion for fracture of a structure and/or its part consists in attainment of the critical crack size $a_{c}$. At this size of crack, the limit state would occur by mechanism of brittle or mixed brittleductile fracture. Regarding the fact that fracture occurrence should be avoided, the admissible crack size must be smaller than the critical. The structures dynamically loaded in service may be loaded either by high-cycle fatigue, strain (low- cycle) fatigue or by irregular fatigue loading. Theoretical background for determining the growth rate of fatigue cracks is sufficiently mastered at present. For crack growth rate at high cycle fatigue, the Paris - Erdogan's (1936) relationship is used, whereas for the strain fatigue the Manson - Coffin's (1954) relationship is applied and at irregular fatigue, the cumulative hypotheses are employed, whereas the most widely used seems to be the Palmgren - Miner's (1945) criterion in conjunction with Wohler's (1860) curve [1].

Present direction in the field of design, manufacture, service, repairs and liquidation of structures is governed by the approaches making use of the theoretical and practical knowledge of the „Fitness For Service - FFS" approach. Documents from this field are accessible on the web site: www.eurofitnet.org.

Application of this theory in fabrication and service of metallic structures is schematically shown in Table 1.

The limit state may occur from several reasons, for example from the material loss of the bulk structure, caused by corrosion. Material degradation may occur due to ageing, distortion of crossbars and due to defect growth by fatigue process, most often by loading caused by the sharp atmospheric influences. 
TABLE I. MODULES OF FITNESS FOR SERVICE" APPROACH.

\begin{tabular}{|c|c|c|c|c|}
\hline $\begin{array}{l}\text { Safety and } \\
\text { service } \\
\text { reliability }\end{array}$ & $\begin{array}{l}\text { Structure } \\
\text { design }\end{array}$ & $\begin{array}{l}\text { Structure } \\
\text { fabrication }\end{array}$ & $\begin{array}{l}\text { Assessment } \\
\text { during life }\end{array}$ & $\begin{array}{l}\text { Analysis of limit } \\
\text { states }\end{array}$ \\
\hline $\begin{array}{l}\text { Information } \\
\text { needed for } \\
\text { assessment }\end{array}$ & $\begin{array}{l}\text { Information } \\
\text { about service } \\
\text { during life }\end{array}$ & $\begin{array}{l}\text { Rate and type of } \\
\text { loading }\end{array}$ & $\begin{array}{l}\text { Mechanical } \\
\text { properties of } \\
\text { material }\end{array}$ & $\begin{array}{l}\text { Extraordinary } \\
\text { effects }\end{array}$ \\
\hline $\begin{array}{c}\text { Possible } \\
\text { failure modes }\end{array}$ & $\begin{array}{c}\text { Fracture (brittle, } \\
\text { ductile) }\end{array}$ & $\begin{array}{c}\text { Distortion } \\
\text { (plastic collapse) }\end{array}$ & Fatigue & Corrosion \\
\hline $\begin{array}{l}\text { Integrity } \\
\text { criteria }\end{array}$ & $\begin{array}{l}\text { Critical defect } \\
\text { size }\end{array}$ & Residual life & Categorisation & Passportisation \\
\hline Application & $\begin{array}{l}\text { Creation of } \\
\text { databases }\end{array}$ & $\begin{array}{l}\text { Utilisation of } \\
\text { databases }\end{array}$ & $\begin{array}{l}\text { Controlled } \\
\text { ageing }\end{array}$ & $\begin{array}{l}\text { Economic } \\
\text { studies }\end{array}$ \\
\hline
\end{tabular}

\section{B. Risk based Inspection}

At present, there are many important high-voltage lines in the age, when the life of pylons is approaching and/or it has already reached the design life. Therefore it is necessary first of all to eliminate in maximum possible measure the dangerous states and risks leading to possible formation of limit state in pylons and at the same time to secure the diagnostics of all pylons older than 40 years.

Repairs and maintenance of pylons are mostly performed just by partial interventions, either of greater or smaller extent and these are performed on the basis of empiric professional judgements. The advances suitable for assessment and continuous diagnostic monitoring of real technical state of pylons during their life has not been developed nor introduced up to now. Any relevant progression for determination of residual life, that would be generally accepted and binding, were elaborated. Since there is considerable disunity in opinions how to proceed in individual cases, it is necessary to elaborate a knowledge-based solution of diagnostics, procedures for maintenance and repairs as well as for replacement of pylons and/or entire lines.

Optimum solution of maintenance and repairs supposes determination of suitable inspection intervals. Their determination follows from the analysis of damage risks (Risk Based Inspection - RBI) [2], as shown in Fig.1. The structure must be capable to tolerate the failures formed between the two inspection intervals. Thus, in spite of existence and growth of damage caused by corrosion and/or dynamic loading, the structure must be safe and functional up to the next planned inspection. Determination of interval of diagnostic inspections directly depends on the admissible probability of failure.

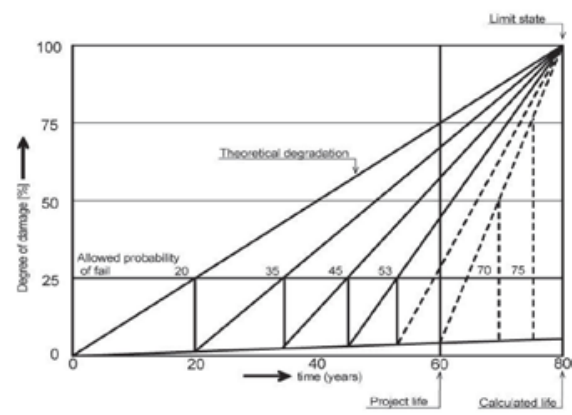

FIGURE I. INTERVALS OF STRUCTURE INSPECTION BY THE RISK BASED INSPECTION THEORY.

\section{SYSTEM OF DIAGNOSTIC MEASUREMENTS}

Diagnostics is destined for an objective determination of factual state of pylon material from the viewpoint of its damage during the service. Modern non-destructive and destructive diagnostic methods used for determination of factual stage of pylon damage allow to obtain a complex picture about the internal and external defects in the critical cross sections, as well as the measure of material damage due to ageing. The scheme of system is shown in Table 2 .

TABLE II. THE SYSTEM OF DIAGNOSTIC MEASUREMENTS.

\begin{tabular}{|l|l|l|l|l|l|l|}
\hline \multicolumn{5}{|c|}{ Diagnosed subject } \\
\hline Material sampling & General visual inspection & \multicolumn{3}{l|}{ Direct NDT inspection } \\
\hline Mechanical tests & $\begin{array}{l}\text { Surface corrosion } \\
\text { UTT }\end{array}$ & \multicolumn{5}{|l|}{ Inspection of critical points } \\
\hline Metallographic studies & $\begin{array}{l}\text { State of surface protection } \\
\text { ET }\end{array}$ & VT & UT & ET & MT & PT \\
\hline Chemical analysis & Distortion of crossbars & \multicolumn{3}{|l|}{ Residual stresses } \\
\hline Transition temperature & State of bases & \multicolumn{2}{|l|}{ Local hardness } \\
\hline \multicolumn{5}{|c|}{ Results of diagnostics } \\
\hline
\end{tabular}

\section{A. Life of Pylons}

The diagnostics grasps the actual state in damage of individual pylons. Based on assessment criteria, the extent of damage is assessed in five degrees, whereas the first degree represents a non-damaged pylon and the fifth degree represent a pylon in emergency condition. The intermediates comprise: slightly, moderately and considerably damaged pylon. The damage degrees are schematically shown in Fig. 2. The damage process of steel structure of pylons progresses in the course of life separately in its individual components (corrosion, ageing, defect growth, distortions of crossbars etc.) but the resultant effect of damage is represented summarily. The degradation process is governed by actual physical and chemical laws, which allow to predict their expected further development, as also seen in Fig.2.

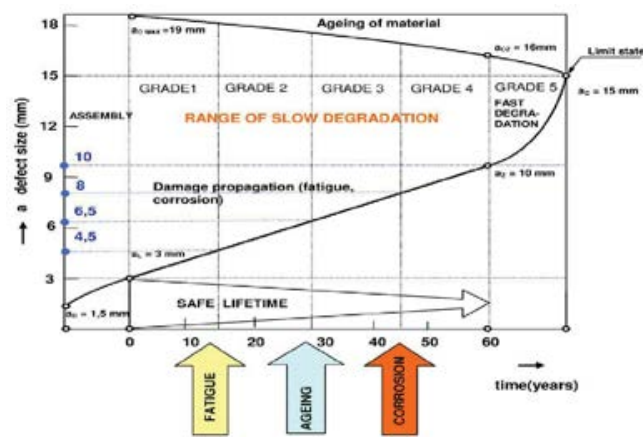

FIGURE II. THE COURSE OF LIFE AND THE DEGREES OF PYLON DAMAGE.

Thus, a real possibility to determine the supposed residual life of pylon structure is created. The individual degradation effect preserve certain specific features, therefore it is necessary to analyse the individual degradation effects separately [3]. The residual life may be determined for each 
individual pylon, however it is recommended to determine it just for the most damaged pylon in each section.

\section{B. Residual Life}

Residual life generally depends on the state in structure damage, on acceptable damage size and on the supposed service conditions in the course of time form diagnostics performance till the end of safe life. Four significant modes of damage may occur on pylon structures which alter during the course of life and affect the residual life of a pylon: material ageing [3], corrosion [4], fatigue crack growth [1], distortion of crossbars.

Determination of supposed residual life is an engineering problem, which solution consists in a unimpeachable estimation of time during which the pylons may be utilised at met requirements for service safety. Residual life of pylons is thus considered till termination of a safe service and not up to reaching the emergency (limit) state. Each of the mentioned damage modes may separately cause the termination of service period, due to exceeding the critical damage size (CDS). The time courses of assessment properties can be obtained on the basis of long-term monitoring of individual damage modes. This allows to achieve the life function of studied property. At individual damage modes, attention should be mainly paid to the following two issues: modes,

- $\quad$ course of the life function at individual damage

- $\quad$ critical degree of degradation (CDS) of an actual damage.

Regarding the fact that the development of individual damage modes, as well as the admissible degree of degradation mutually differ, since they are of different physical or chemical essence, it is necessary to approach to individual damage modes separately.

\section{CONTROLLED AGEING}

Integrity of pylons must be ensured continually. The quality systems have introduced the principle of responsibility of manufacturer and operator for the safety of product, in our case the lines of high-voltage during the entire period of their technical life. This requirement may be ensured by the method of controlled ageing of pylons. Principle of controlled ageing consists in the fact that a complex diagnostics with subsequent maintenance (eventually also repairs) of all defective points is performed in the intervals defined in advance [5]. After such action the structure gets to its ,initial" state. However, the material degradation caused by ageing will remain a permanent change that cannot be removed. These intervals are determined by the RBI (risk based inspection) method, as shown in Fig. 3.

Controlled ageing has a direct effect upon two most important performance criteria, namely the service reliability and Life Cycle Cost (LCC). However, also time of safe service is prolonged. On the side of expenditures, the costs for diagnostics, maintenance and repairs are involved, whereas on the side of savings a prolonged time of safe life of pylons is obtained. Practice have shown, that the cost for controlled ageing are considerable lower, than the savings obtained by prolonged time of safe service with postponing of new investment.
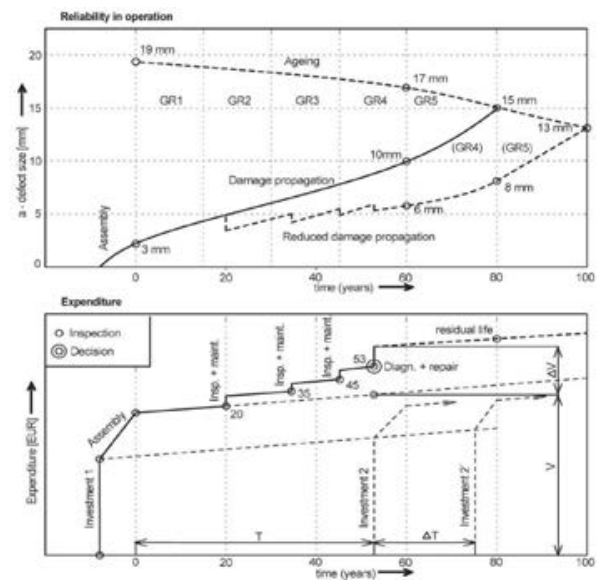

FIGURE III.

THE COURSE OF CONTROLLED AGEING AND DATA ANALYSIS.

\section{A. Passportisation and Database of Pylons}

Precondition for introduction of system of controlled ageing consists in creation of passportisation of pylons. Each pylon has its passport with given all basic data necessary for further analyses in the course of life, as shown in Table 3.

TABLE III. MAIN DATA IN PASSPORT.

\begin{tabular}{|l|l|l|}
\hline $\begin{array}{c}\text { Fabrication and putting } \\
\text { to service }\end{array}$ & $\begin{array}{l}\text { External effects in the } \\
\text { region of location }\end{array}$ & \multicolumn{1}{|c|}{$\begin{array}{c}\text { Realised repairs and } \\
\text { maintenance }\end{array}$} \\
\hline Locality (map) & $\begin{array}{l}\text { Temperature range, icing } \\
\text { zone }\end{array}$ & $\begin{array}{l}\text { Replacement of crossbars or } \\
\text { other parts (splice bars etc.) }\end{array}$ \\
\hline Line designation & Band of precipitation & Replacement of accessories \\
\hline Pylon designation & Band of wind speed & Replacement of ropes \\
\hline Drawing documentation & $\begin{array}{l}\text { Maximum windstorm } \\
\text { degree in the region }\end{array}$ & Replacement of insulators \\
\hline Static calculation - standard & Landslides & Renewal of paints \\
\hline Date of pylon erection & Seismic effects & Removal of scrub, soil \\
\hline Date of putting into service & $\begin{array}{l}\text { Area of infestation - } \\
\text { industry }\end{array}$ & Repair of foundations \\
\hline Pylon material & $\begin{array}{l}\text { Area of infestation - } \\
\text { chemistry }\end{array}$ & Other repairs \\
\hline Used joints: welds/bolts & Other effects & Other maintenance \\
\hline Filler metal & Notes & Notes \\
\hline Other data & & \\
\hline
\end{tabular}

Individual lines were put into service at different time. It is quite apparent that all input data will not be available for the older line sections. However, this is by no means an obstacle for creation of databases of actual present state. A database is actually a defined set of passports with all relevant data for performing the analyses of actual state and plan of maintenance, repairs and/or reconstruction. All tests and measurements must be performed by an authorised institution. Database is continually completed with all data connected with the service of pylons, as the results of occurring during the line life, realised maintenance and so on.

\section{DISCUSSION AND CONCLUSIONS}

Research of life of pylons in high-voltage lines has shown the possibilities for realisation of repairs, maintenance and replacement on the basis of scientific approach [6]. In some 
cases of loading of carrying pylons it is necessary to perform also other non-standard tests, as for example fatigue tests, tests of crack growth rate, determination of fracture toughness, tensometric (strain rate) measurements, rigidity measurements and detection of resonance frequency of a pylon. In order to assure the service reliability, as well as the optimum economical usage of transmission system, it is advisable to elaborate and implement the program of controlled ageing of transmission system. This will then allow to monitor and assess the effect of service and degradation processes on individual components of transmission line, to observe the trends in changes of their state and to accept early the precaution measures for removing and/or moderating the causes of ageing. The program of controlling ageing is one of preconditions allowing to prolong the residual life of transmission system. Finally it must be emphasised that determination of residual life is neither cheap nor simple. This supposes introduction of a system for observing the „life" of pylons starting with design up to discarding from service (decommissioning).

\section{ACKNOWLEDGEMENTS}

This contribution was prepared within the APVV-0434-11 project.

\section{REFERENCES}

[1] Hobbacher, A. "Recommendations for Fatigue Design of welded Joints and Components." Doc. IIW-1823-07, 2007.

[2] Sinay, J. "Risks of technological equipment." Technical University of Košice, Košice, 1997.

[3] Hrivnak, I. "Welding and Weldability of Materials." Slovak Technical University, Bratislava, 2009.

[4] Polak, P. "Corrosion Cracks Propagation Velocity." Welding Research Institute, Bratislava, 1998.

[5] Danis, D. "Controlled Ageing of Blocks of Atomic Power plants VVER 440." AT\&P Journal, 10/2005.

[6] Kocak, M. "FITNET fitness-for-servis procedure: an overview" IIW, Welding in the World, vol. 51 no.5-6. 